\title{
AID ECONOMETRICS: \\ LESSONS FROM A \\ STOCHASTIC GROWTH MODEL
}

\author{
Patrick Carter
}

Discussion Paper 15 / 659

22 May 2015

ARISTOL

Department of Economics

University of Bristol

8 Woodland Road

Bristol BS8 1TN

United Kingdom 


\title{
Aid Econometrics: lessons from a stochastic growth model
}

\author{
Patrick Carter \\ University of Bristol and the Overseas Development Institute
}

June 2015

ABSTRACT

This paper evaluates the standard empirical methods employed in the study of foreign aid, when the data generating process is a calibrated stochastic growth model in which aid recipients make optimal investment and consumption decisions. When recipients receive a stochastic flow of aid and wish to smooth consumption, standard methods fail to distinguish between the response to transient and permanent aid shocks, and hence yield misleading results concerning the object of interest to policy makers: the long-run impact of aid.

Keywords: Foreign Aid, Stochastic Growth Model, Convergence, Local Projections, Consumption Smoothing. JEL Codes: F35; C51.

Email: paddy.carter@bristol.ac.uk. Thanks to Jonathan Temple, and to seminar participants in Bristol for helpful advice. All errors are the responsibility of the author. Financial assistance from the ESRC and British Academy under awards ES/I901876/1 and PF110079 respectively, and the Royal Economic Society Junior Fellowship Scheme is gratefully acknowledged. 


\section{Introduction}

This paper asks what foreign aid researchers will find using standard empirical methods when the true data generating process is a stochastic growth model in which aid recipients make optimal saving decisions. The answer is that they would identify long-run effects of aid on investment and output even though none are present in the data by construction, and understate the long-run effect on consumption. The reason is that standard empirical methods do not distinguish between transitory and permanent components of aid, and wrongly infer a long-run response from the short-run response to transitory variation.

The empirical literature on foreign aid tends to treat permanent and temporary components of aid variation as interchangeable. This means that, in conventional regressions, the estimated effect of aid will depend on the type of events in the data - without knowing more, it is hard to say would regressions would identify. The object of interest from a policy perspective is usually the long-run macroeconomic response to a long-lasting change in the average (or expected) level of aid that a country receives, not the response to short-run fluctuations.

Standard growth regressions also produce potentially misleading results because they are misspecified; they make no allowance for the effect aid has on the speed of convergence and position aid solely as a determinant of steady-state output. In the basic neoclassical model with optimizing agents, aid accelerates convergence but does not raise steady-state output (Obstfeld, 1999).

The analysis of foreign aid in a stochastic growth model has two implications for empirical research: first, it would be desirable to identify changes in the expected level of aid that a country receives and estimate the dynamic response of macroeconomic variables to that; second, empirical models which allow aid to influence the rate of convergence may be fruitful.

The distinction between transitory and permanent variation has long been emphasized in the consumption literature, and in intertemporal models of the current account. ${ }^{1}$ One contribution of the present paper is simply to draw attention to the relevance of these ideas in the context of foreign aid. Neglect of these ideas may be an instance of generational

\footnotetext{
${ }^{1}$ Jappelli and Pistaferri (2010) survey the theory and empirical methods employed to study consumption, Obstfeld and Rogoff (1995) covers current account models.
} 
forgetting. Stigler (1977) proposes a numbering system for generic comments on economics papers. Number 12 is: "The analysis is marred by a failure to distinguish transitory and permanent components."

As, for example, (Deaton, 1997, p. 352) shows, in the context of the relationship between income and consumption, it is possible to distinguish between transitory and permanent variation if one can find an instrument that is correlated with permanent component of income but orthogonal to the transitory component. ${ }^{2}$ In the aid literature, instruments based on donor budgets, such as in Werker et al. (2009) and Temple and Van de Sijpe (2015), could potentially be seen in this light, with the proviso that variation in donor budgets must be expected to be persistent. The approach taken by Galiani et al. (2014) and Dreher et al. (2015) most closely resembles a direct implementation of this idea, and is based on graduation from the World Bank's development assistance program. The issues raised in this paper also strengthen the case for studying the long-run effect of aid in cross section, as in Arndt et al. (2013) and Rajan and Subramanian (2008).

Existing theoretical guidance for empirical aid research is largely based on the deterministic Solow model. The most prominent example is Rajan and Subramanian (2008), which provides a theoretical derivation of the coefficient empirical researchers would find on the aid term in a growth regression, when aid recipients are Solow economies. ${ }^{3}$ The derivation is based on the assumption that a fixed proportion of any increase in aid is invested, without regard for the prevailing marginal return to capital and the expected duration of the aid increase. ${ }^{4}$ This assumption shuts down potentially crucial aspects of a recipient's response to aid variation.

The data generating process studied in this paper is a calibrated stochastic neoclassical growth model, in which countries receive an exogenous stochastic flow of foreign aid and recipients make optimal consumption and investment decisions. A representative

\footnotetext{
${ }^{2}$ Suppose consumption is a function of transitory and permanent income $C_{t}=\alpha+\beta_{1} y_{t}^{P}+\beta_{2} y_{t}^{T}+u_{t}$. The permanent income hypothesis suggests $\beta_{1}=1$ and $\beta_{2}=0$. Observed income can be decomposed as $y_{t}=y_{t}^{P}+y_{t}^{T}$ and the equation $C_{t}=\alpha+\beta_{1} y_{t}+\left(\beta_{2}-\beta_{1}\right) y_{t}^{T}+u_{t}$ can be estimated using an instrumental variable that is correlated with $y_{t}^{P}$ but orthogonal to $y_{t}^{T}$, and the error term becomes $\left(\beta_{2}-\beta_{1}\right) y_{t}^{T}+u_{t}$.

${ }^{3}$ As of June 2015 Rajan and Subramanian (2008) has over 540 citations on Google Scholar and over 320 citing articles according to the Web of Science, without self-citations. It was cited 200 times in 2013. The extremely influential paper Burnside and Dollar (2000), cited over 2500 times excluding self-citations, was motivated by a deterministic neoclassical growth model with optimal saving: see the unpublished appendix available on Craig Burnside's website.

${ }^{4}$ Foreign aid is highly volatile in the short run (Bulîr and Hamann, 2008).
} 
household in each recipient economy receives a flow of aid from a known recipient-specific stochastic process with a constant unconditional mean, so for each recipient economy all variation in aid is transient, but there are permanent differences in the level of mean aid across recipients. In each period households take consumption and investment decisions with the objective of maximizing lifetime welfare, facing the prevailing marginal return to capital. Recipient households are assumed to have no access to international capital markets, hence they can only smooth consumption by varying investment, which is assumed to be irreversible so households cannot respond to negative shocks by consuming the capital stock.

To make the analysis as relevant as possible, it will be conducted on a simulated dataset of the same dimensions as that available to empirical researchers, and the data generating process will be calibrated to match certain features of the data, such as the distributions of aid levels and volatility, and the distributions of output growth rates and volatility, across countries. The calibration includes setting each economy's initial level of capital per worker. Most of the simulated economies are initially far beneath their balanced growth paths, and recipients will use aid to accelerate investment, as the economy undergoes transition dynamics. In this setting empirical researchers would hope to identify the effect of aid on investment, consumption and output growth.

The empirical methods investigated will largely be single-equation models estimated on panel data, reflecting a common choice of estimators in the aid literature. However, in the context of estimating the dynamic response to transitory aid shocks, the more novel Local Projections methods introduced by Jorda (2005) will be evaluated, and non-linear least-squares will also be used to examine whether aid affects the speed of convergence. The Local Projections method has been introduced to the aid literature by Jarotschkin and Kraay (2013).

It is perhaps more usual to evaluate empirical methods via Monte Carlo simulations in which true structural parameters are known, and the focus is on how accurately estimators recover those parameters. Hauk and Wacziarg (2009) is a particularly relevant example. There is also a large literature concerning the estimation of structural parameters in macroeconomic models. ${ }^{5}$ The approach taken here differs from these strands of research in that

\footnotetext{
${ }^{5}$ See DeJong and Dave (2011) for a textbook treatment, and references therein. Carroll (2001) is an
} 
the estimating equations employed are known to be misspecified, and the parameters are not of direct interest. Rather we want to know how well standard empirical models recover the qualitative nature of the relationships between foreign aid and macroeconomic variables. The relative simplicity of the basic stochastic growth model is helpful here, because it provides some straightforward qualitative predictions to test empirical models against. Empirical research into foreign aid is orientated towards questions of policy such as: what is the nature of the relationship between aid and economic growth? The long-run response to a lasting increase (or decrease) in aid is of primary interest. This paper asks how well existing empirical methods perform from this perspective.

The remainder of this paper proceeds as follows. Section 2 briefly surveys the theoretical backdrop to empirical aid research, and contrasts the dynamics of aid in the neoclassical growth model with the dynamics imposed by a conditional convergence growth regression. Section 3 sets out the calibrated stochastic neoclassical growth model that is used to generate the simulated datasets on which the analysis is based, and section 4 illustrates the role of consumption smoothing in this setting and how it may mislead researchers who are interested in the long-run effects of aid. Section 5 presents the empirical analysis and shows what researchers would find using standard empirical methods on these data. Section 6 provides a brief discussion, before a concluding final section.

\section{Context}

Empirical research into the macroeconomic effects of foreign aid is dominated by reducedform single-equation regressions. Recent surveys of the empirical aid-growth literature can be found in Arndt et al. (2010), Mekasha and Tarp (2013) and discussion in Temple (2010). Many authors have focussed on the problem of endogenous aid allocation and on the role of recipient characteristics that may influence aid effectiveness, such as the policy environment. A reduced-form approach is taken because aid may affect recipient economies in numerous ways, and researchers are interested in general equilibrium outcomes.

Existing theoretical guidance for empirical researchers tends to be based on simple

antecedent of the present paper, in its use of simulated data to demonstrate that standard empirical methods - in this case those used to estimate consumption Euler equations - produce misleading results. 
models. Easterly (2003) describes the influence of the "two-gap" model of Chenery and Strout (1966), but the Solow model is the standard theoretical benchmark for empirical aid research, as in Rajan and Subramanian (2008). When theory is used, it is usually to help in 'formulating an appropriate prior' (Arndt et al., 2010) concerning the magnitude of the estimated coefficient on foreign aid in a growth regression. The stochastic properties of the model and implications for the interpretation of regression results are less often explored.

Two papers by Binder and Pesaran (1999) and Lee et al. (1997) do focus on the implications of a stochastic data generating process for empirical research, although they are not concerned with foreign aid and study a data generating process with exogenous rather than optimal investment decisions. They derive the long-run and time-series properties of a stochastic Solow model, discuss appropriate empirical models, and present some empirical results. Arellano et al. (2009) study the effects of aid volatility on consumption, investment and the structure of production in a two-sector model, and demonstrate the predictions of the model are consistent with cross-country evidence.

The distinction between transitory and long-run effects of aid is not entirely new to the literature. Rajan and Subramanian (2008) write "the issue of key interest is the longrun impact of aid: aid could mechanically increase output and growth in the short run but this is not what economists care about". One contribution of the present paper is to show that the empirical methods put to work in papers like Rajan and Subramanian (2008) may produce misleading estimates of those long-run effects that economists care about. The authors also mention possible effects on convergence, writing "we are interested in whether aid takes a country to its ultimate steady-state potential (or to a higher steadystate if it improves the country's potential growth) faster".

\subsection{The dynamics of aid in the neoclassical growth model}

The neoclassical growth model is a particularly relevant case for study in the context of aid research because the modal empirical paper is an extension of a 'Barro' conditional convergence regression (Barro and Sala-i Martin, 1992), derived by linearizing the neoclassical growth model around the steady-state as in Mankiw et al. (1992).

In the deterministic neoclassical model with optimizing agents, where foreign aid is 
treated as a transfer of real resources and recipients take optimal decisions, the steady-state level of income is unaffected by the level of aid, but aid-funded investment will accelerate convergence to the steady-state. The logic behind this result can be seen in the analysis of Obstfeld (1999). The steady-state is reached once the additional lifetime utility achieved by investing and raising the path of future consumption no longer justifies the required sacrifice of current consumption, at which point the representative household no longer wishes to accumulate capital. The associated level of capital is pinned down by structural parameters, and the origin of the income that the household must allocate between consumption and investment, be it domestic production or foreign aid, is immaterial. A corollary of the invariance of the steady-state to aid is that aid is wholly consumed in steady-state.

The fact that aid accelerates convergence but does not affect the steady-state, when agents optimize, implies a rather subtle relationship between aid and the rate of growth. An economy receiving a fixed flow of aid when beneath steady-state will initially grow more rapidly than in a zero-aid counterfactual, but after a period of years the growth rate of the economy receiving aid will decline beneath that of the zero-aid counterfactual. Based on the calibration in Obstfeld (1999) this occurs after roughly five years. This apparent negative impact of aid on growth happens because the rate of growth declines as convergence proceeds, and aid accelerates convergence. But this does not mean that aid retards growth at any point; conditional on the capital-labor ratio the impact of aid on growth is strictly positive at all times. The subtlety is that when comparing the growth rates over time of an economy receiving aid against a zero-aid counterfactual, aid changes the capital-labor ratio on which the growth rate is conditional.

In contrast, the conditional convergence regression that is typically employed in empirical aid research implies quite different dynamics. In its simplest form the empirical model

$$
y_{i t}-y_{i t-1}=\alpha_{i}-\lambda y_{i t-1}+\beta \text { aid }_{i t}+u_{i t}
$$

implies a steady-state $y_{i}^{*}=\left(\alpha_{i}+\beta a i d_{i}^{*}\right) / \lambda$ and the speed of convergence is pinned down by $\lambda$. In this model aid determines the level of the steady-state but has no impact on 
the speed of convergence. As written equation (1) has a zero-growth steady-state. Technological progress, and hence long-run growth, is usually introduced via time dummies in a panel setting (thus imposing homogeneity across countries) or is subsumed by the constant term in a cross section regression, and is thus independent of aid in both cases. Aid-growth regressions of this form are better suited to the dynamics of aid in the Solow model, but are misspecified when agents make optimal investment decisions. ${ }^{6}$

The dynamic implications of aid in the neoclassical model are easy to miss, even without optimizing agents. The coefficient on aid derived by Rajan and Subramanian, who study aid in the Solow model, is described as how much we can expect aid to "raise the longrun growth rate" (Rajan and Subramanian, 2008, p. 659). But it is actually the effect of an increase aid at the point in time that it is applied, which fades to zero over time (which is also how the coefficient $\beta$ in equation (1) should be interpreted). The equation the authors derive for the rate of output per capita growth, assuming some fraction $s^{a}$ of aid is invested, is:

$$
\gamma_{y}=\alpha s^{a} \frac{\text { Aid }}{Y} \frac{Y}{K}+\alpha s \frac{Y}{K}-\alpha(n+\delta)+\gamma_{A}
$$

where $\gamma_{y}$ is the growth rate of output per capita, $\gamma_{A}$ is the rate of technological progress and $s$ is the fraction of domestic output saved, $\alpha$ the output elasticity of capital and $n$ and $\delta$ the rates of population growth and depreciation, respectively. ${ }^{7}$ But as output grows and the capital stock converges to steady-state, $\frac{Y}{K}$ will fall until eventually $\alpha s^{a} \frac{\operatorname{Aid}}{Y} \frac{Y}{K}+\alpha s \frac{Y}{K}=\alpha(n+\delta)$ and output per capita grows at the rate of technological progress. When an exogenous proportion is saved, aid increases the steady-state level of capital and output. A permanent increase in the flow of aid would initiate transition dynamics, but have no impact on the growth rate once the economy has converged to its new steady-state. ${ }^{8}$

\footnotetext{
${ }^{6}$ Some brief (and unsuccessful) attempts to use non-linear least squares to capture the effect of aid on the speed of convergence are reported in an online appendix to this paper.

${ }^{7}$ This formulation corrects a minor error in the original which had $\alpha \gamma_{A}$ and also replaces $I_{p}$ in the original, an exogenous quantity of private (non-aid funded) investment, with $s Y$, so that an exogenous fraction $s$ of output is saved, in the spirit of the original Solow model. The authors use the average value of $Y / K$ in their data, and $\alpha=0.35$, to compute an expected coefficient on Aid $/ Y$, when expressed as a percentage, of 0.0016 when aid is wholly invested $\left(s^{a}=1\right)$ implying increasing aid by 1 percentage point raises output growth by 0.16 percentage points, on impact.

8 In a Solow model calibrated to match Rajan and Subramanian (2008), in an economy receiving an aid flow equivalent to 1 percent of initial GDP the rate of output growth compared to a zero-aid counteractual is 0.16 percentage points higher at $t=0,0.10$ percentage points higher at $t=5$ and 0.065 percentage points higher at $t=10$.
} 


\section{The data generating process}

The simulated data studied in this paper are generated by a variant of the neoclassical discrete-time stochastic growth model, as developed by Brock and Mirman (1972) among others. Panel datasets of dimension $N=127$ and $T=40$ are generated by solving and simulating the model $N$ times. Each aid recipient is a closed economy simulated in isolation and there are no economic interactions or cross-country correlations in the stochastic processes. To wash out the effects of idiosyncratic draws from the stochastic processes, $M$ such datasets are generated and the empirical results reported are averages over these $M$ iterations, in much the same way as multiple iterations are used in Monte Carlo simulations.

The $N$ and $T$ dimensions mimic those available to empirical researchers, and correspond to the number of observations of low and middle-income countries with population greater than one million for which there are available aid data (based on World Bank income classifications, Penn World Table version 7.1 and OECD DAC aid disbursements data). A longer $T$ would be possible at the cost of a smaller $N$. A subset of the parameters of the model vary across individual economies, including the initial conditions (distance from steady-state) assumed when simulating the model. The calibration of these parameters is described in section 3.1 .

Two additions are made to the basic model, the first being that each country receives a stochastic flow of aid, in the form of a transfer of real resources. The second is the introduction of a capital distortion, so that each unit of consumption goods only buys $1 / \pi<1$ units of investment goods. The distortion introduces variation in capital-output ratios across countries, as observed in the data, and would justify the use of a fixed-effects regression in an empirical setting, to account for unobserved cross-country heterogeneity. Interpreted literally, this distortion is the price of investment goods in terms of consumption goods, a variable widely thought to explain a good deal of cross-country income variation (Hsieh and Klenow, 2007). It may be interpreted more broadly as a reduced-form expression of various distortions affecting investment outcomes, such as allocative efficiency, the risk of expropriation and the cost of bribes. 
The representative household has the objective of maximizing expected lifetime utility

$$
\max _{C_{t}} \sum_{t=0}^{\infty} \beta^{t} E_{t} u\left(C_{t}\right)
$$

Subject to

$$
\begin{aligned}
& K_{t+1}=1 / \pi\left\{Z_{t} F\left(K_{t}, A_{t}, L_{t}\right)+A i d_{t}-C_{t}\right\}+(1-\delta) K_{t} \\
& Z_{t} F\left(K_{t}, A_{t}, L_{t}\right)+A_{i} d_{t}-C_{t} \geq 0
\end{aligned}
$$

where the capital distortion $\pi$ varies across economies but is assumed to be a constant. The production function will be assumed to be Cobb-Douglas. Technology has a stochastic and a trend component, $Z_{t}$ and $A_{t}$ respectively. Each household supplies labor inelastically, so the household size equals the labor force $L_{t}$ and grows at the rate $n$, and the level of labour-augmenting technology $A_{t}$ grows at the rate $g$. Both of these growth rates are assumed to be global constants. The two stochastic processes are technology $Z_{t}=\mu^{z} e^{\left(v_{t}^{z}\right)}$ and $A i d_{t}=\mu^{a} e^{\left(v_{t}^{a}\right)}$. Both $v_{t}^{z}$ and $v_{t}^{a}$ are modeled as $A R(1)$ processes:

$$
\begin{aligned}
& v_{t}^{z}=\rho^{z} v_{t-1}^{z}+\varepsilon_{t}^{z} \\
& v_{t}^{a}=\rho^{a} v_{t-1}^{a}+\varepsilon_{t}^{a}
\end{aligned}
$$

where $\varepsilon_{t}^{z} \sim N\left(-0.5 \sigma^{z}, \sigma^{z}\right)$ and $\varepsilon_{t}^{a} \sim N\left(-0.5 \sigma^{a}, \sigma^{a}\right)$. The parameters $\rho^{z}$ and $\rho^{a}$ vary across economies and are calibrated, as are the variances of the shock processes $\sigma^{z}$ and $\sigma^{a}$. The unconditional means of $\varepsilon_{t}^{z}$ and $\varepsilon_{t}^{a},-0.5 \sigma^{z}$ and $-0.5 \sigma^{a}$, are chosen so that $E\left[e^{\left(v_{t}\right)}\right]=1$ in both cases. Hence $\mu^{z}$ and $\mu^{a}$ are the (constant) unconditional means of $Z_{t}$ and Aid $_{t}$, normalized to 1 in the case of technology but varying across countries in the case of aid.

A non-negativity constraint is imposed on gross investment, with the result that the long-run distribution of capital is not affected by the expected level of aid. This is perhaps an extreme assumption; some forms of capital can be consumed (such as livestock). Without this constraint, the ability to consume the capital stock provides insurance against negative technology shocks. Foreign aid reduces the need for such insurance by providing 
an alternative means of consumption smoothing, so the optimal capital stock is lower in the presence of foreign aid (Arellano et al., 2009).

When the model is simulated, at time $t$ investment is chosen according to the household's optimal policy function, on the basis of observed realisations of output and aid. In an empirical setting, output at time $t$ is predetermined, in the sense it does not respond to aid at time $t$. The rate of output growth measured between the periods $t_{0}$ and $t_{1}$ is determined by investment in period $t_{0}$ and the realisation of the technology process in period $t_{1}$, not aid. So it would be natural to use lagged aid in a growth regression, but contemporaneous aid in an investment regression.

The model is made stationary in the usual way, by dividing variables by the two quantities that exhibit trend growth, $L$ and $A$, for example $k=K / A L$ is capital per effective worker. This entails transforming the discount rate using the rates of population growth and technological progress $n$ and $g$ as follows: $\hat{\beta}=\beta\{(1+g)(1+n)\}^{(1-\sigma)}$. Each recipient's expected level of aid is constant in efficiency units aid / $A L$, which amounts to implicitly assuming the existence of a donor in steady-state whose aid budget is growing at the global trend rate $n+g$.

The long-run mean of capital per effective worker is affected by the variance of the technology and aid processes, but simulations demonstrate that for the range of calibrated shocks employed in this paper, deviations of the long-run mean from the deterministic steady-state level of capital are small..$^{9}$ The deterministic steady-state is:

$$
k^{*}=\left\{\frac{1}{\pi} \frac{\alpha}{\gamma / \hat{\beta}-(1-\delta)}\right\}^{\frac{1}{(1-\alpha)}}
$$

where $k=K / A L$. The variables $Y_{t}, K_{t}, C_{t}, A i d_{t}$ will be treated as observable, without measurement error. The capital distortion $\pi$ will be treated as unobservable.

\footnotetext{
${ }^{9}$ For a recipient with parameters set at the calibrated sample means, changing the variances of stochastic processes from zero to the individual-country maximum found in the calibration, the long-run average level of capital per effective worker remains within the range 2.17 to 2.21 . The deterministic steady-state under this average parameterization is 2.19. See Stachurski (2002) for derivations of the long-run distribution of capital in the presence of unbounded shocks and references for the bounded case. The numerical solution and simulation of the model employed in this paper entails using a bounded approximation for an autoregressive stochastic processes with normally distributed innovations.
} 


\subsection{Calibration}

The intention is to provide a theoretical environment that is sufficiently realistic to be of interest to empirical researchers. In this regard the properties of the stochastic processes are more important than other structural parameters, which only have a modest effect on the magnitude of the response to aid but do not alter qualitative predictions. Consequently the parameters $\alpha=0.4, \beta=0.98, \delta=0.06, \sigma=1.5, n=0.02, g=0.01$ are set at values common in the literature.

Parameters for the technology process are chosen by combining the assumed aggregate production function with data on output, labour and estimated capital stocks, to generate a Solow residual, or total factor productivity, series and then running $A R(1)$ regressions on this quantity, for each country. All data are taken from the Penn World Table version 7.1. This yields a value of $\rho^{z}$ for each $N$ recipient, and a value of $\sigma^{z}$ that corresponds to the variance of the residuals from each of these regressions. ${ }^{10}$ The success of this approach can be seen in Table 1, which compares moments of the simulated data against corresponding moments computed from the Penn World Table 7.1. The calibration is based on moments such as the standard deviation of output or the mean level of aid/GDP and aims to match the distribution of these objects across countries.

The stochastic processes for aid are calibrated in similar fashion by running AR(1) regressions for each country, on aid per capita. The more conventional measure of aid as a proportion of GDP is not used, to avoid conflating the volatility of aid with the volatility of GDP. Values for $\mu^{a}$, the unconditional mean of the aid process, are simply the mean levels of aid as a proportion of recipient GDP in the data.

Initial conditions for each recipient are calibrated by attempting to match the distribution of average output growth rates across countries in the data. Initial conditions are drawn from a Cauchy distribution, so the calibration entails choosing its location (median) and scale (dispersion). As Table 1 shows, even with the flexibility of a fat-tailed distribution it was not possible to fully match the dispersion of growth rates seen in the data. ${ }^{11}$ So in

\footnotetext{
${ }^{10}$ In practice $\rho^{z}$ is capped at 0.98 , which affects a handful of countries, because the algorithm used to approximate an AR(1) process performs less well as $\rho$ approaches 1.

11 Two avenues for raising the variance of simulated rates of output growth could be to hit economies with occasional and large shocks (of either sign) to the permanent component of trend productivity growth, as suggested by Aguiar and Gopinath (2007), or to replace the fixed capital distortion $\pi$ with a stochastic process, perhaps one subject to regime changes as in Chari et al. (1997).
} 
Table 1: Calibration: moments

\begin{tabular}{lcc}
\hline Moment & PWT data & Simulated data \\
\hline \hline Std. Dev ln $Y$ & & \\
Mean & 0.22 & 0.20 \\
Std. Dev & 0.13 & 0.09 \\
Min & 0.04 & 0.03 \\
Max & 0.76 & 0.97 \\
Mean annual growth $Y$ & & \\
Mean & 0.015 & 0.014 \\
Std. Dev & 0.021 & 0.004 \\
Min & -0.03 & 0.005 \\
Max & 0.088 & 0.025 \\
Mean aid $Y$ & & \\
Mean & 0.06 & 0.06 \\
Std. Dev & 0.06 & 0.07 \\
Min & 0.00 & 0.00 \\
Max & 0.03 & 0.04 \\
Mean K/Y & & \\
Mean & & 1.76 \\
Std. Dev & 2.33 & 0.60 \\
Min & 1.13 & 0.40 \\
Max & 0.37 & 6.36 \\
\hline \hline Tis Tablempar
\end{tabular}

This Table compares moments from the simulated data against corresponding moments computed from PWT7.1. Std. Dev $\ln Y$ is the standard deviation of the logarithm of real output per capita, computed for each country over a 40 year period. Mean annual growth $Y$ is the geometric mean of annual output growth rates. Mean aid $/ Y$ is the mean ratio of net official development assistance to GDP, both series in current dollars. Mean $K / Y$ is the mean capital-output ratio for each country computed over 40 years. Capital stock estimates computed by perpetual inventory method.

this respect the simulated data has too little variation.

The capital distortions $\pi$ are calibrated by matching the theoretical deterministic steadystate capital-output ratios to mean capital-output ratios taken from the data. The precision of the calibration of this parameter is not central in this context. Investment data from developing countries are likely to include a good deal of measurement error, and some capital-output ratios taken from the PWT are higher than the model implies with $\pi=1$ whilst others are implausibly low. Capital-output ratios below the 10th and above the 90th percentile were discarded. The moments reported for $K / Y$ in Table 1 reflect the results of this cull. This left fewer than $N$ calibrated values for $\pi$, so for each simulated recipient $\pi$ was chosen as a random draw from this trimmed set. The distribution that $\pi$ is drawn 
from is independent of the distribution of aid across countries. However, amongst the $M$ replications the dataset, there is often a correlation between the mean level of aid and the (unobserved) capital distortion, that would bias cross-country regressions and motivate the use of fixed-effects estimators.

\section{Consumption smoothing}

An important feature of this data generating process is that the recipient household has no ability to smooth aid flows by borrowing or lending on international markets. This is clearly an extreme assumption, and it means that when aid flows are volatile, the only available instrument with which to smooth consumption is to vary investment in synchronization with aid.

Aid recipients are often selected specifically because they have limited access to international credit markets, but it would probably be more realistic to grant aid recipients some ability to smooth volatile aid flows, if only by accumulating a buffer stock of saved aid. However the assumption of zero access is retained here to show the potential implications of consumption smoothing for the interpretation of empirical results, and avoids taking a stand on the nature of financial frictions faced by aid recipients and the extent to which investment bears the brunt of consumption smoothing in reality.

Although the present model abstracts from government, it is worth noting that recipient governments do have limited scope for aid smoothing. Buffie et al. (2010) explain that the internal pressures to spend aid money as it arrives are strong, and also that donors are highly averse to recipients accumulating buffer stocks of aid, but rather "want to see their money spent doing good", putting aid recipients in a use-it-or-lose-it position. In addition to funding investment, aid is often used to finance recurring expenditures like education and health spending, or nutrition and income support programs targeted at the poor, which aid recipients may wish to insulate from external funding volatility, much like the representative household in the current model wishes to smooth consumption.

In this setting, consumption smoothing entails a dramatic response to transitory variation in aid, and implies a complicated cross-sectional relationship between aid and growth in these data. Looking across countries in any given period, a country receiving a high level 
Figure 1: What consumption smoothing means for investment, when aid is volatile

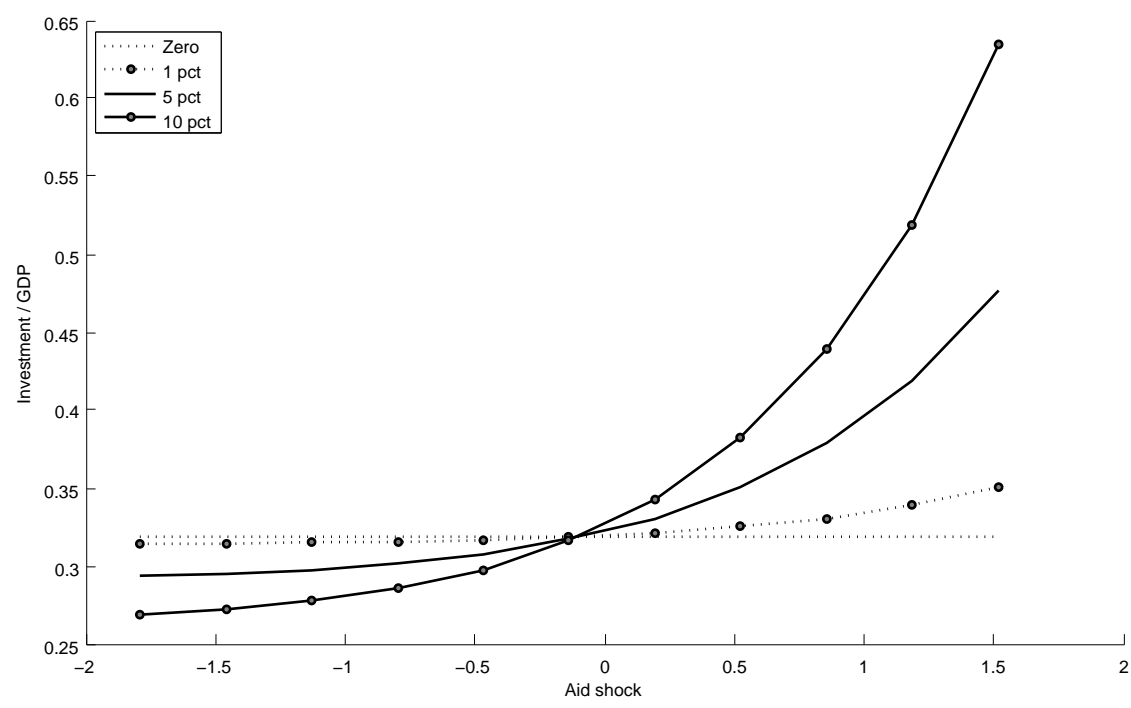

This figure shows optimal investment as a function of realisations of the stochastic process for aid, for different levels of expected aid. The figure is derived from the policy function that gives optimal investment at different points in the state space, shown here for a given level of capital and realisation of the technology process. The level of capital chosen here is roughly 30 per cent beneath steady-state, corresponding to the average initial condition in the simulated data generating process. The policy function is qualitatively the same at other levels of capital, including at the long-run mean. The realisation of the technology process is $e^{\left(v_{t}^{z}\right)}=1$. The flow of aid received in period $t$ is $\mu^{a} e^{\left(v_{t}^{a}\right)}$ where $\mu^{a}$ is expected aid and $v_{t}^{a}$ is an AR(1) stochastic process, such that $E\left[e^{\left(v_{t}^{a}\right)}\right]=1$. The $\mathrm{x}$-axis shows realisations of $v_{t}^{a}$.

of aid may invest less, and hence grow more slowly, than a country with lower aid, even when both countries are equally far beneath steady-state. This occurs whenever the low aid country experiences a higher-than-average realisation from its aid process, whilst the high aid country is experiencing a lower than expected realisation. Figure (1) shows the optimal investment rate for various levels of expected aid, as a function of the realisation of the stochastic process for aid, at a given level of the capital stock. The horizontal dotted line shows optimal investment under a zero aid regime, and the extent to which investment undershoots that level for negative realisations of the aid shock grows as expected aid increases. When the realisation of aid corresponds to its expected level, so $e^{\left(v_{t}^{a}\right)}=1$, which is labeled as aid shock equals 0 in the figure, investment increases with aid, but only modestly so. So although low aid countries may sometimes grow faster than high aid countries, on average aid raises the rate of output growth, when given to countries undergoing transition dynamics.

Another way to see the contrast between the response of investment to transitory and 
permanent variation is to ask the sort of question an empirical researcher may seek to answer, such as: how will investment respond if aid is increased from 5 per cent of GDP to 10 per cent? There are two ways to see that in the data generating process under consideration here. We may compare investment in a recipient with expected aid of 5 per cent against a recipient with expected aid of 10 per cent (and the aid shock set such that $e^{\left(v_{t}^{a}\right)}=1$ in both cases) or we may measure the investment response when an economy receiving mean aid of 5 per cent experiences a positive aid shock, such that $e^{\left(v_{t}^{a}\right)}=2$. Figure (2) shows just that. It is based on the optimal policy function at different levels of capital, and shows the change in optimal investment when aid is increased from 5 to 10 per cent by means of a positive aid shock (solid line) and when expected aid is varied (dotted line). The investment response to transitory variation in aid is much higher, reflecting the role of consumption smoothing.

This relationship between the transitory and permanent components of aid and investment (and hence output growth) in a stochastic growth model contrasts with the findings of Galiani et al. (2014), where the estimated impact a permanent change in the expected level of aid is much larger than is typical in the aid-growth literature, when no attempt is made to distinguish between the transitory and permanent components of aid. ${ }^{12}$ One possible explanation for that result could be that aid recipients are able to smooth away transitory variation in aid, but not a permanent change.

\subsection{Misinterpreting the long-run effects of aid}

Aid research is primarily focussed on the response of macroeconomic variables to variations in expected aid, although this is rarely precisely stated. Less formally, policy makers are interested in the long-run effects of some long-lasting change to the average quantity of aid that a country receives over time. In the presence of consumption smoothing, standard empirical methods are misspecified because they treat the transitory and permanent components of aid as interchangeable. In their simplest form, the standard approach is to estimate an equation like:

\footnotetext{
${ }^{12}$ However in Dreher et al. (2015) an estimated positive impact of aid on growth, at the regional, level disappears once aid is instrumented with graduation from the World Bank's concessional lending window.
} 
Figure 2: The impact of variation in aid on investment: comparing transitory and permanent variation

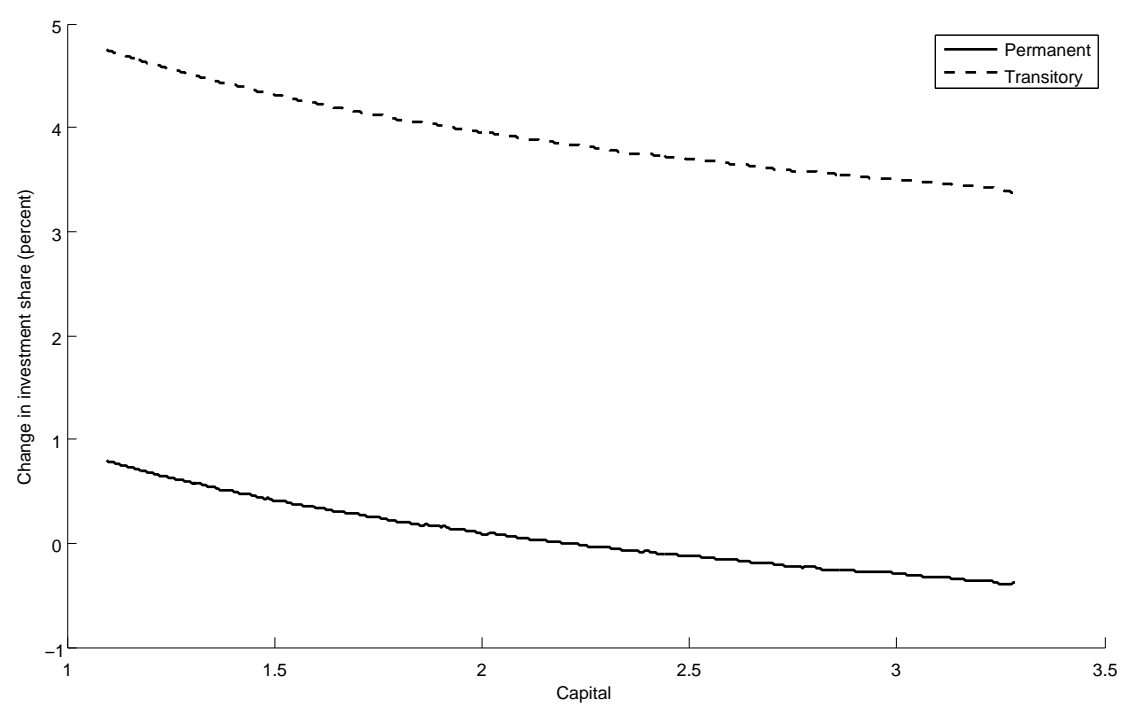

This figure shows the percentage change in the investment share when aid is increased from 5 per cent of GDP to 10 per cent. It is computed from the policy function, which gives the optimal saving decision at different levels of capital and realisations of the stochastic processes. The solid line represents the impact of permanent variation in aid, and is the difference in the investment share comparing an economic receiving mean aid of 5 per cent and against one with mean aid of 10 per cent (and for aid and technology shocks set such at $e^{\left(v_{t}\right)}=1$ ). The dotted line captures the impact of transitory variation, and is the difference in the investment share between an economy with mean aid of 5 per cent and $e^{\left(v_{t}^{a}\right)}=1$ and the same economy experiencing a positive transitory aid shock such that $e^{\left(v_{t}^{a}\right)}=2$ which means aid is doubled to 10 per cent of GDP (and the technology shock is $\left.e^{\left(v_{t}^{z}\right)}=1\right)$ ).

$$
y_{t}=\eta+\rho y_{t-1}+\beta a_{t}+u_{t}
$$

where $y_{t}$ is some macroeconomic variable, $a_{t}$ is aid and $u_{t}$ an error term. Based on this estimated model, a policy maker wishing to know the long-run impact of a permanent one-unit increase in $a_{t}$ effect on $y$ would be given the answer $\beta /(1-\rho) .{ }^{13}$ In the stochastic data generating process with optimizing agents studied in this paper, which does not correspond to the empirical model in equation (3), we know that parameter estimates obtained from a fixed-effects estimator will be based on transitory variation only and $\beta /(1-\rho)$ does not give us the long-run response to variation in the expected level of aid, which is zero by construction.

\footnotetext{
${ }^{13}$ Here 'long-run' means $t \rightarrow \infty$. More generally resesarchers may be interested in effects of aid that persist over a number of years, if not forever.
} 
An alternative approach could be to estimate a pair of equations, or VAR:

$$
\begin{aligned}
& y_{t}=\mu^{y}+\rho^{y} y_{t-1}+\beta a_{t}+u_{t} \\
& a_{t}=\mu^{a}+\rho^{a} a_{t-1}+e_{t}
\end{aligned}
$$

where the unconditional mean of aid is $\mu^{a} /\left(1-\rho^{a}\right)$ and we are exploiting the knowledge that aid is exogenous and excluding $y$ from equation (5), and we can assume $e_{t}$ and $u_{t}$ are independent. A natural next step would be compute a impulse response function to trace out the response of $y$ to either a one-off, or permanent, shock to $e_{t}$. But again the question posed by a policymaker interested in increasing aid should be understood, in this illustrative example, as wishing to know the response to a change in $\mu^{a}$, expected aid, not the response to realisations of the stochastic process $e_{t}$. The impulse-response to a 'permanent shock' would paint a misleading picture; when a country receives a permanent flow of aid, it does not receive a sequence of positive shocks.

One potential response to the present paper is that it demonstrates that aid potentially has no (or little) effect on output and investment in the long run, and hence empirical researchers should seek to identify short-run effects. Furthermore, if we accept that the bulk of the variation in aid data is transitory and fixed-effects estimates exploit this variation, then perhaps existing empirical strategies are acceptable.

The analysis of aid in the neoclassical model does indeed suggest that researchers should study its effects on transition dynamics that play out over the medium term, but it remains necessary to differentiate between the response to transitory shocks and the response to variation in the average quantity of aid received over a given period. The existence of positive shocks presupposes the existence of negative shocks, and as Figure (1) shows, the investment response to a positive aid shock is offset by the response to a negative shock. Hence even if the focus is on the medium-run empirical research must identify the effect of aid on average over time. The key point is that the immediate response of aid recipients to a transitory shock is a fundamentally different object to how recipients respond to variation in the expected quantity of aid received over some period. 


\section{Empirical Analysis}

This section presents the results of running a selection of regressions on the simulated panel datasets, and compares estimated relationships with those we know to exist in the data generating process.

The main focus of the analysis will be on the estimated long-run impact of aid on investment, consumption and output, which corresponds to the main focus of empirical aid research. Methods to estimate the short-run response to aid shocks, and the impact of aid on the speed of convergence, will also be briefly examined.

The data generating process, set out in section 3, produces a balanced panel with aid, output, consumption and investment data for $N=127$ aid recipients over $T=40$ years. No measurement error is introduced. Consumption and investment are measured as a percentage of domestic output, and in all periods investment plus consumption equals output plus aid. Data for each recipient are generated by simulating the model, using calibrated parameters and initial conditions (see section 3.1) and draws from the two stochastic processes, aid and technology. In small samples, idiosyncratic draws from these processes may create a spurious statistical association between aid and other variables. To wash out such effects, $M=500$ simulated panels are generated and the analysis will be based on averages over these $M$ iterations, in much the same way as multiple iterations are used in Monte Carlo studies. Each results table will report the mean parameter estimate, the standard deviation of estimates over iterations and the proportion that are reported as statistically significant at the 5 per cent level, based on Huber-White robust standard errors.

The empirical methods assessed will be panel estimators - the fixed-effects estimator and GMM panel estimators - where the time dimension is exploited to allow for unobserved time-invariant heterogeneity across countries. These estimators dominate empirical research into the macroeconomic effects of aid. Researchers have begun to adopt time-series techniques (VARs and VECMs) common in macroeconomics, such as Juselius et al. (2014), whilst others, seeking to estimate long-run effects of aid, have turned to cross-section regressions, such as Arndt et al. (2013) and Rajan and Subramanian (2008). But in the context of forward-looking consumption and investment decisions, VAR-based estimates of a longrun response to a permanent aid shock are not of interest, because it makes little sense 
to suppose aid is higher than expected forever, whilst cross-section regressions would be confounded by the correlation between aid and the unobserved capital distortion $\pi$.

In the data generating process aid has no long-run effect on the level of investment or output and a one-for-one long-run effect on consumption. ${ }^{14}$ These predictions are the yardstick against which the performance of estimators will be measured. Results will be presented for estimates based on annual frequency data and four-year averages. Although some empirical research still uses pooled panel methods with annual data, it is generally regarded as preferable to use longer-duration averages, in an attempt to smooth away business-cycle frequency effects, and four-year averages are most common (see Clemens et al. (2012) for example). As we shall see, this practice is not sufficient to cleanse estimates of the effects of transitory shocks.

GMM estimators will only be applied to the 4-yearly data, because the finite sample autoregressive bias (Nickell, 1981), which motivates their use, would not be a concern when $T=40$. Both 'difference' GMM (Arellano and Bond, 1991) and 'system' GMM (Blundell and Bond, 1998) will be applied, although the stationarity assumption that validates the use of differences as instruments for levels in the system GMM estimator may be violated in this setting. ${ }^{15}$ Additionally, the knowledge that aid is exogenous permits the application of a bias correction procedure based on Kiviet (1995), which will also be reported. ${ }^{16}$ Unlike GMM estimators, this procedure does not rest on assumptions about the exogeneity of lagged variables, nor is it prone to weak instrument problems.

It is perhaps worth emphasizing that GMM estimators and bias-correction procedures address problems that arise when estimating dynamic fixed-effects models, where the estimating equation corresponds to the data generating process. They do not address the model misspecification inherent in using a linear model to estimate the effects of aid in a dynamic stochastic general equilibrium model. They are investigated here because of their popularity in applied work.

To evaluate short-run predictions, the yardstick will be an impulse response function

\footnotetext{
${ }^{14}$ More precisely, as described in section 3, the volatility of the aid process has a tiny effect on the long-run average level of capital, and hence investment and output.

15 This assumption amounts to requiring that differences are not correlated with fixed effects - in this context that initial conditions are not correlated with the capital distortion. See Roodman (2009) for more detail.

16 The procedure is based on the generalization by Bruno (2005) and standard errors are bootstrapped.
} 
computed from the policy function of the solved model. In more detail, the model will be simulated for an average recipient, and the simulated paths of investment, consumption and output in the wake of a one-off one-unit shock to aid will be compared against paths under a simulated zero-shock counterfactual, to compute a 'true' impulse response. This will then be visually compared against that predicted by two empirical methods: an estimated by an auto-regressive model, and the Local Projections method introduced by Jorda (2005), a more flexible method for estimating dynamic responses in time series. This comparison is only heuristic, but instructive nonetheless.

\subsection{Investment and consumption}

This section evaluates the estimated long-run impacts of aid on investment and consumption against the true long-run impacts, which are zero and one-for-one, respectively. In the data, variation in the long-run level of investment is determined by the country-specific capital distortion $\pi_{i}$, which will also affect the short-run response to aid. The presence of such cross-country heterogeneity motivates the use of a fixed-effects or GMM estimator.

Although aid-growth regressions constitute the bulk of empirical research into foreign aid, attempting to identify the relationship between aid and the growth rate of income per capita presents the empirical researcher with some formidable challenges. In addition to general problems such as measurement error and endogenous aid allocation, to estimate an output growth regression researchers must grapple with unobserved levels and growth rates of total factor productivity across countries. ${ }^{17}$

Table 2 presents results from running dynamic investment regressions on annual data and data averaged over four years. Two aid terms are included to allow for a positive effect on impact but a zero long-run effect. ${ }^{18}$ The mean estimated coefficients, averaged over 500 simulated datasets, are reported, together with the standard deviation across datasets and

\footnotetext{
17 Another problem is that output series are typically persistent, which potentially limits the amount of useful information in panel data. In the context of this data generating process, output is a function of a slow-changing state variable (capital), whereas investment is a jump variable. So, setting aside the problems raised in this paper, econometricians can expect more useful variation in investment data, and face fewer difficulties identifying the relationship with aid.

${ }^{18} \mathrm{Lag}$ selection procedures suggest one lag of investment, contemporaneous aid and once-lagged aid is the optimal choice, but columns 2 and 4 present results with more lags of aid to illustrate a more flexible lag structure does not eliminate the estimated positive long-run impact of aid. Lag selection based on Akaike's corrected information criterion, using the Furnival-Wilson algorithm for all subsets.
} 
the proportion that are statistically significant at the 5 per cent level (and of the same sign as the mean). In all cases a positive long-run effect of aid on investment is estimated, which does not exist in the data generating process. Using data averaged over four years does not eliminate this effect. Of the estimators tested here, System GMM fares best in the sense that the estimated long-run effect is smallest. The standard deviation of estimates across datasets is higher for the GMM estimators, especially for the lagged dependent variable. ${ }^{19}$

Table 2: Estimated impact of aid on investment

\begin{tabular}{|c|c|c|c|c|c|c|c|c|}
\hline \multirow{2}{*}{\multicolumn{2}{|c|}{$\begin{array}{l}\text { Estimator } \\
\text { Period }\end{array}$}} & FE & FE & FE & $\overline{F E}$ & $\overline{\text { Diff }}$ & Sys & Kiviet \\
\hline & & $1 \mathrm{yr}$ & $1 \mathrm{yr}$ & $4 \mathrm{yr}$ & $4 \mathrm{yr}$ & $4 \mathrm{yr}$ & $4 \mathrm{yr}$ & $4 \mathrm{yr}$ \\
\hline \multirow[t]{3}{*}{ L.inv } & mean & 0.799 & 0.776 & 0.528 & 0.436 & 0.536 & 0.585 & 0.645 \\
\hline & $\mathrm{sd}$ & 0.016 & 0.018 & 0.038 & 0.061 & 0.258 & 0.164 & 0.044 \\
\hline & pct sig & 1 & 1 & 1 & 1 & 0.68 & 0.9 & 1 \\
\hline \multirow[t]{3}{*}{ aid } & mean & 0.593 & 0.589 & 0.471 & 0.479 & 0.531 & 0.451 & 0.488 \\
\hline & $\mathrm{sd}$ & 0.046 & 0.047 & 0.050 & 0.059 & 0.070 & 0.080 & 0.067 \\
\hline & pct sig & 1 & 1 & 1 & 1 & 0.99 & 0.973 & 1 \\
\hline \multirow[t]{3}{*}{ L.aid } & mean & -0.508 & -0.503 & -0.298 & -0.268 & -0.33 & -0.394 & -0.371 \\
\hline & $\mathrm{sd}$ & 0.042 & 0.040 & 0.046 & 0.054 & 0.155 & 0.076 & 0.054 \\
\hline & pct sig & 1 & 1 & 1 & 1 & 0.68 & 0.98 & 1 \\
\hline \multirow[t]{3}{*}{ L2.aid } & mean & & 0.012 & & 0.004 & & & \\
\hline & sd & & 0.019 & & 0.044 & & & \\
\hline & pct sig & & -0.25 & & -0.1 & & & \\
\hline \multirow[t]{3}{*}{ L3.aid } & mean & & -0.005 & & 0.016 & & & \\
\hline & $\mathrm{sd}$ & & 0.028 & & 0.043 & & & \\
\hline & pct sig & & -0.1 & & -0.15 & & & \\
\hline \multirow[t]{3}{*}{ L4.aid } & mean & & 0.007 & & & & & \\
\hline & sd & & 0.022 & & & & & \\
\hline & pct sig & & -0.15 & & & & & \\
\hline \multirow[t]{3}{*}{ L5.aid } & mean & & -0.001 & & & & & \\
\hline & $\mathrm{sd}$ & & 0.021 & & & & & \\
\hline & pct sig & & -0.15 & & & & & \\
\hline \multirow[t]{3}{*}{ lraid } & mean & 0.425 & 0.442 & 0.368 & 0.412 & 0.433 & 0.134 & 0.328 \\
\hline & sd & 0.068 & 0.083 & 0.089 & 0.103 & 0.379 & 0.151 & 0.145 \\
\hline & pct sig & 1 & 1 & 0.95 & 0.95 & 0.74 & 0.64 & 0.91 \\
\hline
\end{tabular}

Dependent variable: investment share of output. The mean and standard deviation of estimated coefficients over 500 simulated $\mathrm{N}=127 \mathrm{~T}=40$ datasets are reported, together with the proportion that are reported as statistically significant at the 5 per cent level. Standard errors on the long-run impact of aid are computed using the delta method, standard errors for the Kiviet-corrected estimates are bootstrapped. For the GMM estimates reported in columns 7 and 8, internal instruments are restricted to lags 2-4 and collapsed. Lag selection is discussed in footnote 18.

Table (3) reports the results of aid-consumption regressions. In this case the true long-

\footnotetext{
${ }^{19}$ Serial correlation and exclusion restriction tests for the GMM estimators are not reported. They are generally satisfactory although $\mathrm{AR}(2)$ correlation in the errors is sometimes indciated, suggesting longer lags should be used as instruments.
} 
run relationship between aid and consumption is one-for-one, which is underestimated in all cases. Estimators that use 4-yearly data and correct for Nickell bias do best, System GMM reports the long-run effect that is closest to one, but again the standard deviation of GMM estimates across simulated datasets is high.

Table 3: Estimated impact of aid on consumption

\begin{tabular}{llccccccc}
\hline Estimator & FE & FE & FE & FE & Diff & Sys & Kiviet \\
Period & & $1 \mathrm{yr}$ & $1 \mathrm{yr}$ & $4 \mathrm{yr}$ & $4 \mathrm{yr}$ & $4 \mathrm{yr}$ & $4 \mathrm{yr}$ & $4 \mathrm{yr}$ \\
\hline \hline L.c & mean & 0.798 & 0.775 & 0.525 & 0.433 & 0.541 & 0.463 & 0.637 \\
& sd & 0.020 & 0.022 & 0.038 & 0.050 & 0.728 & 0.335 & 0.047 \\
& pct sig & 1 & 1 & 1 & 1 & 0.2 & 0.57 & 1 \\
aid & mean & 0.396 & 0.399 & 0.514 & 0.512 & 0.477 & 0.574 & 0.512 \\
& sd & 0.055 & 0.056 & 0.060 & 0.068 & 0.103 & 0.105 & 0.067 \\
& pct sig & 1 & 1 & 1 & 1 & 0.96 & 1 & 1 \\
L.aid & mean & -0.282 & -0.266 & -0.213 & -0.151 & -0.210 & -0.106 & -0.269 \\
& sd & 0.046 & 0.049 & 0.047 & 0.054 & 0.368 & 0.223 & 0.052 \\
& pct sig & 1 & 1 & 1 & 0.85 & 0.11 & 0.2 & 1 \\
L2.aid & mean & & -0.005 & & -0.010 & & & \\
& sd & & 0.024 & & 0.043 & & & \\
& pct sig & & 0.23 & & 0.13 & & & \\
L3.aid & mean & & 0.000 & & -0.019 & & & \\
& sd & & 0.024 & & 0.041 & & & \\
L4.aid & pct sig & & 0.16 & & 0.16 & & & \\
& mean & & -0.002 & & & & & \\
& sd & & 0.023 & & & & & \\
L5.aid & pct sig & & 0.16 & & & & & \\
& mean & & -0.002 & & & & & \\
LR aid & sd & 0.018 & & & & & \\
& pct sig & & 0.13 & & & & & \\
& mean & 0.564 & 0.546 & 0.633 & 0.583 & 0.615 & 0.851 & \\
& pd sig & 0.086 & 0.101 & 0.119 & 0.146 & 0.756 & 0.170 & \\
\hline
\end{tabular}

Dependent variable: consumption share of output. The mean and standard deviation of estimated coefficients over 500 simulated $\mathrm{N}=127 \mathrm{~T}=40$ datasets are reported, together with the proportion that are reported as statistically significant at the 5 per cent level. Standard errors on the long-run impact of aid are computed using the delta method, standard errors for the Kiviet-corrected estimates are bootstrapped. For the GMM estimates reported in columns 7 and 8, internal instruments are restricted to lags 2-4 and collapsed. Lag selection is discussed in footnote 18.

\subsection{Aid and growth}

Because output growth is a function of investment in the prior period (and the realisation of the technology shock process) the short-run investment response to aid shocks carries over into a growth regression, the workhorse model of the empirical aid literature. Columns 
1 and 3 of Table 4 are simple regression of growth on lagged aid, to illustrate the raw correlation, whilst all other columns are conditional convergence regressions. A second lag of aid is included to allow for a positive impact effect but zero long-run effect. Although the dependent variable is output growth, all these models impose a zero-long run effect of aid on growth (the dynamics are similar to those of the Solow model described in section 2.1). The long-run estimate reported in the last row of the table is the long-run semielasticity of the level of output per capita. No long-run estimates are reported for the GMM estimators because the positive estimated coefficients on lagged log output are inconsistent with stability.

This exercise illustrates the possibility of finding what looks like a positive impact of aid on output per capita, when the underlying mechanism is actually investment volatility created by consumption smoothing in the face of a volatile aid flow.

Although it reflects the short-run investment response to transitory variation, and not a lasting impact of aid on growth of the sort that empirical researchers seek, aid does have an effect on output growth in the data generating process, and we are able to compare the magnitude of the estimated impact of lagged aid with its theoretical counterpart. The mean estimated coefficient on lagged aid in model 2 of Table 4 of 0.0007 suggests that a 1 percentage point increase in the level of aid/GDP in period $t-1$ is associated with a 0.07 percentage point increase in the growth rate, on impact. This corresponds reasonably well to a theoretical approximation based on the estimates in Table (2), which imply that a 1 percentage point increase in the level of aid/GDP is associated with a 0.6 percentage point increase in the gross investment share of output. A rough calculation based on the assumed production function and average values for each variable suggests that the implied increase in the capital stock would produce a 0.08 percentage point increase in the rate of output growth, on impact.

\subsubsection{Brueckner / Bond et al. growth regressions}

An interesting alternative to conditional convergence regressions is estimated in Brueckner (2013). Empirical models of this type have been used to test the predictions of endogenous growth models, by distinguishing between short and long-run effects of investment, and 
Table 4: Estimated impact of aid on output growth

\begin{tabular}{|c|c|c|c|c|c|c|c|c|}
\hline \multicolumn{2}{|c|}{ Estimator } & FE & FE & FE & FE & Diff & Sys & Kiviet \\
\hline \multicolumn{2}{|l|}{ Period } & $1 \mathrm{yr}$ & $1 \mathrm{yr}$ & $4 \mathrm{yr}$ & $4 \mathrm{yr}$ & $4 \mathrm{yr}$ & $4 \mathrm{yr}$ & $4 \mathrm{yr}$ \\
\hline \multirow[t]{3}{*}{ L.ln $(y)$} & mean & & -0.048 & & -0.156 & 0.055 & 0.002 & -0.070 \\
\hline & sd & & 0.007 & & 0.026 & 0.133 & 0.051 & 0.027 \\
\hline & pct sig & & 1 & & 1 & 0.04 & 0.04 & 1 \\
\hline \multirow[t]{3}{*}{ L.aid } & mean & 0.001 & 0.0007 & 0.0028 & 0.0016 & 0.003 & 0.002 & 0.002 \\
\hline & sd & 0.0002 & 0.0002 & 0.0009 & 0.0009 & 0.001 & 0.001 & 0.001 \\
\hline & pct sig & 0.99 & 0.9 & 0.93 & 0.58 & 0.87 & 0.59 & 0.76 \\
\hline \multirow[t]{3}{*}{ L2.aid } & mean & & -0.0001 & & 0.0003 & 0 & -0.001 & 0.000 \\
\hline & sd & & 0.0002 & & 0.0008 & 0.001 & 0.001 & 0.001 \\
\hline & pct sig & & 0.11 & & 0.07 & 0.09 & 0.25 & 0.10 \\
\hline \multirow[t]{3}{*}{ LR aid } & mean & & 0.0149 & & 0.0129 & & & 0.046 \\
\hline & $\mathrm{sd}$ & & 0.0059 & & 0.008 & & & 0.049 \\
\hline & pct sig & & 0.87 & & 0.44 & & & 0.77 \\
\hline
\end{tabular}

Dependent variable: $\ln \left(y_{t}\right)-\ln \left(y_{t-1}\right)$ and the explanatory variable aid is $(A i d / G D P) * 100$. The estimate labelled $L R$ aid is the long-run impact of aid on the level of log output. The mean and standard deviation of estimated coefficients over 500 simulated $\mathrm{N}=127 \mathrm{~T}=40$ datasets are reported, together with the proportion that are reported as statistically significant at the 5 per cent level. Standard errors on the long-run impact of aid are computed using the delta method, standard errors for the Kivietcorrected estimates are bootstrapped. For the GMM estimates reported in columns 7 and 8 , internal instruments are restricted to lags 2-4 and collapsed.

other variables, on the rate of output growth. Jones (1995) is an early example of this line of research.

Equation 6 is a simplified version of the main regression specification in Brueckner (2013). ${ }^{20}$ Equation 7 is designed to test the predictions of the Solow model that aid effects the level of output but not the long-run growth rate. The estimated coefficient on the loglevel of aid would capture a long-run growth effect, whilst the log-difference terms reflect effects on the level of output.

$$
\begin{aligned}
& \Delta \ln y_{t}=\beta_{0} \Delta \ln \text { aid }_{t}+v_{1}+u_{i t} \\
& \Delta \ln y_{t}=\beta_{1} L . \Delta \ln y_{t}+\beta_{2} \Delta \ln \text { aid }_{t}+\beta_{3} L . \Delta \ln \text { aid }_{t}+\ln \text { aid }_{t}+v_{1}+u_{i t}
\end{aligned}
$$

Table (5) shows the results of these regressions, again averaged over 500 iterations, using annual data and four-year averages, and using aid/GDP and aid per capita as explanatory

\footnotetext{
${ }^{20}$ Shorn of control variables and the two-stage procedure designed to adjust for the negative reverse causal effect of GDP per capita growth on foreign aid, which is the main contribution of Brueckner (2013), but irrelevant here because aid is exogenous.
} 
variables. Normalizing aid by GDP may be problematic when estimating the effect of changes in aid on changes in output. To see why, suppose a mean-reverting productivity shock takes three values (positive, zero and negative), being zero on average, and suppose aid is a constant. If this shock reverts from high to zero, from one period to the next, then GDP growth will be negative whilst aid/GDP will have risen, introducing a potential spurious negative correlation. A rough and ready fix in the current setting is to use aid per capita as explanatory variable, because population grows as the same trend rate as aid, so the spurious correlation problem does not arise. The magnitudes of the estimated coefficients on aid $/ Y$ and aid $/ L$ are not comparable; we are interested in the sign and statistical significance of the estimates.

When aid /GDP is the explanatory variable, estimated coefficients reported in Table (5) are negative. $^{21}$ The estimated coefficient on the log-level of aid is also frequently positive and significant, when using aid/GDP, suggesting an effect on long-run growth that we know not to exist in the data. When aid per capita is used, the average estimated coefficients on the log-difference of aid are positive when using four-year averages, but rarely statistically significant. We know aid does increase the rate of output growth on impact, on average, in these data, but these regressions provide no evidence of that.

Table 5: Brueckner (2013) growth regressions

\begin{tabular}{lcccccccc}
\hline Model & 1 & 2 & 3 & 4 & 5 & 6 & 7 & 8 \\
\hline \hline D.ln(aid) & -0.018 & -0.020 & -0.001 & -0.001 & -0.029 & -0.035 & 0.003 & 0.004 \\
& $(1.00)$ & $(1.00)$ & $(0.15)$ & $(0.10)$ & $(1.00)$ & $(0.95)$ & $(0.15)$ & $(0.10)$ \\
L.D.In(aid) & & -0.002 & & 0.002 & & 0.007 & & 0.007 \\
& & $(0.20)$ & & $(0.20)$ & & $(0.15)$ & & $(0.15)$ \\
$\ln$ (aid) & & 0.0037 & & 0.001 & & 0.015 & & 0.002 \\
& & $(0.55)$ & & $(0.05)$ & & $(0.30)$ & & $(0.05)$ \\
L.D.In(y) & & -0.005 & & -0.003 & & 0.138 & & 0.142 \\
& & $(0.05)$ & & $(0.05)$ & & $(0.85)$ & & $(0.90)$ \\
\hline Reps & 500 & 500 & 500 & 500 & 500 & 500 & 500 & 500 \\
Frequency & $1 \mathrm{yr}$ & $1 \mathrm{yr}$ & $1 \mathrm{yr}$ & $1 \mathrm{yr}$ & $4 \mathrm{yr}$ & $4 \mathrm{yr}$ & $4 \mathrm{yr}$ & $4 \mathrm{yr}$ \\
Aid Var & Aid/Y & Aid/Y & Aid/L & Aid/L & Aid/Y & Aid/Y & Aid/L & Aid/L \\
\hline \hline
\end{tabular}

Dependent variable: $\ln \left(y_{t}\right)-\ln \left(y_{t-1}\right)$. Fixed effects estimates on simulated $N=127 T=40$ panel, coefficients are averages over 500 replications, number in brackets shows the proportion of replications in which the estimated coefficient is statistically significant at the 5 per cent level. The first four columns are estimated on annual frequency data, last four columns on 4-year averages. Aid relative to GDP is used in columns $1,2,5,6$ and aid per capita in $3,4,7,8$.

${ }^{21}$ Brueckner (2013) mainly uses aid per capita as the explanatory variable, and uses aid/GDP only when drawing comparisons with the Solow model. However, he does not find a negative association between aid and growth when using aid/GDP. 


\subsection{The response to transitory variation}

This paper has argued that the object of primary interest to empirical researchers is the long-run response of the economy to variation in expected aid. However, the dynamic response to transitory variation in aid may be important in some contexts. This section investigates methods for estimating this response, and compares the impulse response functions estimated by Local Projections, a method introduced in Jorda (2005), against more conventional time-series methods. The Local Projections method computes impulse responses without specification and estimation of the underlying multivariate dynamic system

Methods will be evaluated by means of visually comparing estimated response functions against a simulated model-based response for an average recipient. This test is only suggestive. A single 'true' response does not exist: in the data generating process the response of macroeconomic variables to a transitory aid shock is heterogeneous across countries, depending on considerations such as distance from steady-state and the magnitude of the capital distortion. Empirical researchers can hope to recover something like an average response, across countries, from the data, but there is no clean theoretical counterpart to empirical estimates.

In this context a particular advantage of Local Projections is that they are less prone to model mis-specification errors. Put differently, the response is not constrained to be a particular combination of estimated coefficients. Rather, the estimated effect of aid on investment, for example, at a 20-year horizon, is simply the estimated coefficient on aid when the dependent variable is investment 20 years hence. In Jorda's method, the impulse response is given by a series of regressions at different time horizons. The local projection impulse responses of investment, output, consumption and aid to a one percentage point pulse in aid, at time $t=0$, are generated by a series of $s$ pooled panel fixed-effect regressions:

$$
x_{i t+s}=\eta_{i}+\beta^{s} \text { aid }_{i t}+\gamma_{1} L . x_{i t}+\gamma_{2} L 2 \cdot x_{i t}+\gamma_{3} L 3 . i n v_{i t}+u_{i t}
$$

where $s$ runs from 0 to $25, x$ is the dependent variable in question and $L$ is the lag operator. The results of lag selection procedures vary across iterations of the simulated 
data, but two lags were most frequently chosen. When output is the dependent variable, contemporaneous aid is excluded from the regression because it has no impact on contemporaneous output in the data generating process. ${ }^{22}$ Experimentation suggests the resulting impulse responses are not materially affected by the choice. The estimated coefficients are again averages over 500 replications. In a 40 year panel, the 25 year response is estimated from variation in aid within the first 15 years, and each year reduction in time horizon adds another year of useable data.

To compute more standard time-series-based impulse response functions, dynamic fixedeffect regressions were estimated on annual frequency data and averaged across 500 replications of the dataset, and the impulse response computed manually by first tracing out the path of aid and using this as an input for the response of other variables.

Impulse response functions were computed using estimated coefficients from the following fixed-effect regression after running an $A R(p)$ regression on aid:

$$
x_{i t}=\eta_{i}+\delta_{0} L \cdot x_{i t}+\delta_{1} L 2 \cdot x_{i t}+\delta_{2} a i d_{i t}+\delta_{3} L \cdot a i d_{i t}+e_{i t}
$$

where $x$ is either consumption, investment or output per capita, as appropriate. This strategy is permissible in this setting because we know that aid is exogenous. Henceforth the IRF computed in this fashion will be referred to as VAR-based.

The model-based response is based on the simulated response to an aid shock equivalent to 1 per cent of GDP, when the simulation is based on the optimal policy function of an average recipient, with all parameters set to their mean values across the 127 calibrated recipients. In particular the mean level of aid is set at 5.5 per cent of initial GDP and the persistence of the aid shock is determined by the mean $\rho^{a}=0.69$. Initial conditions in the simulation are set to the mean distance from steady-state, over $T$ and $N$, in the $M$ samples. $^{23}$ The model-based impulse response function is computed by subtracting

\footnotetext{
${ }^{22}$ The estimated coefficient on contemporaneous aid would be negative, because positive technology shocks imply higher GDP is associated with lower contemporaneous aid/GDP on average, and impulse response functions using contemporaneous aid describe a strongly negative initial impact and a more moderate negative long-run response to aid.

${ }^{23}$ As opposed to the mean initial distance from steady-state over $N$ in the sample, because empirical estimates are based on aid shocks received as countries converge and so, on average, in the data each economy's distance from steady-state will be smaller than at time zero.
} 
the path of each variable under a zero-shock counterfactual from the paths after the aid shock. ${ }^{24}$

Figure 3: Impulse Response Functions

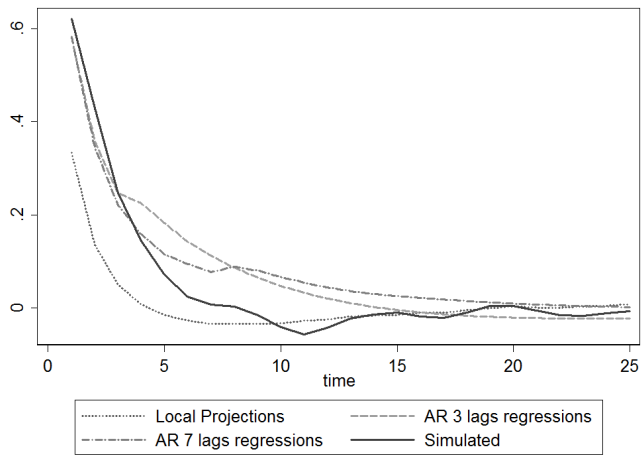

(a) Investment

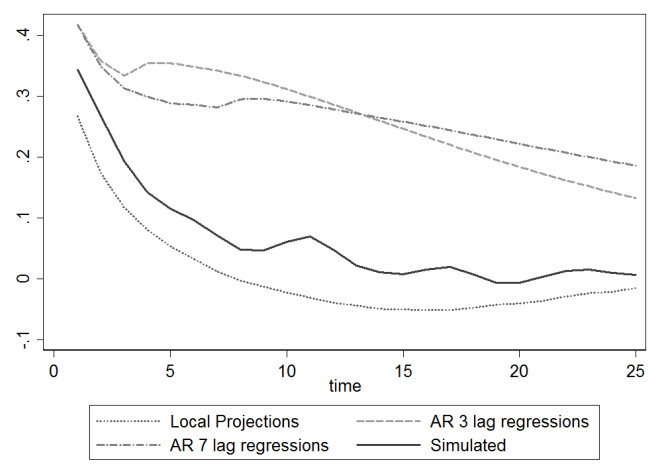

(c) Consumption

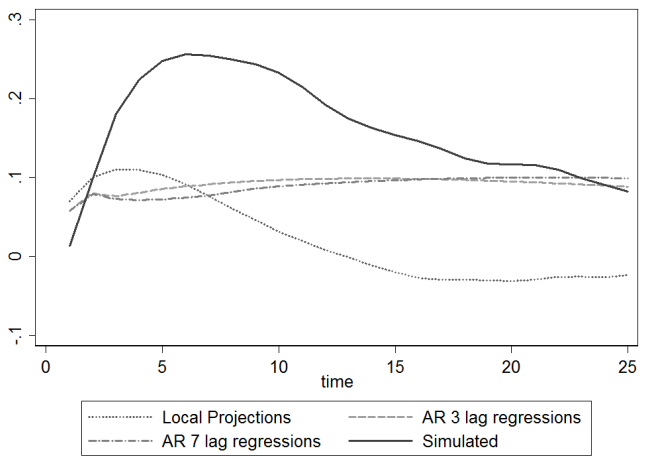

(b) Output

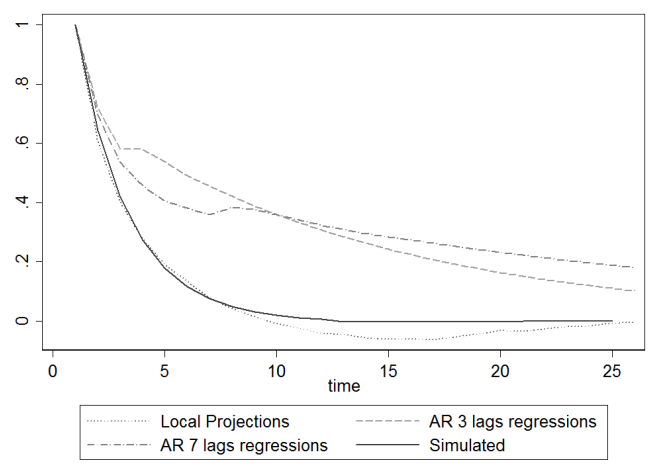

(d) Aid

This figure shows impulse responses to a one percentage point increase in aid / GDP at time $t=0$, based on simulating the model and as estimated by local projections and two estimated by a VAR. The two VAR-based response functions use different choices of $p$ in the $A R(p)$ aid regression.

Figure (3) shows that the local projections appear to be much closer to the model-based response than the VAR-based responses, with the exception of the output case. This may again be explained by the fact that in the data, higher values of aid/GDP occur both because of positive shocks to aid and negative shocks to GDP, whereas in the model-based response only aid is shocked. The VAR-based response is initially closer to the model when more lags are used in the $A R(p)$ aid regression (the two choices of $p$ illustrated are 3 and 7), but in general the VAR-based responses overstate the persistence of the aid shock. These results show that misspecification problems with linear autoregressive models

\footnotetext{
24 This procedures entails some inaccuracies from the combination of discretization and interpolation used to compute policy functions, which is evident in the jagged lines in the figures.
} 
are potentially severe and suggest empirical researchers may prefer the Local Projections method.

Despite its advantages, the Local Projections method does not abrogate the need to decompose aid into permanent and transitory components. As with a standard VAR, a cumulative impulse response function to a 'permanent shock' to aid can be computed, but in this setting that amounts to estimating the response to holding the aid shock above average forever, but with the recipients choosing investment on the basis that they expect aid to fall. The problem remains that the response to transitory and permanent aid shocks differ.

\section{Discussion}

This paper has drawn attention to problems that might matter in theory, but not necessarily in reality. The validity of this case study does not rest on whether the basic neoclassical growth model is an acceptable representation of the growth process in developing countries

- it is not - but rather on whether the mechanisms at work in the model, investment being used to smooth consumption and aid to accelerate convergence, are at work in reality.

There is a large literature on consumption smoothing in developing countries, Townsend (1995) provides an overview. On a macro level a recent paper by Brueckner and Gradstein (2013) report that for a sample of 36 countries in sub-Saharan Africa, consumption responds very little to rainfall-induced transitory GDP shocks, whilst the domestic savings rate responds strongly. Mendoza and Oviedo (2006) explain the stylized facts of fiscal policy in developing countries by proposing a model in which governments try to smooth private sector consumption in the face of volatile revenues, having only limited access to credit markets. But Ghosh and Ostry (1995) find that developing countries are generally able to use the current account to smooth consumption, in contrast to the assumption of this paper that domestic investment is the only available instrument.

There is empirical evidence for a short-run relationship between aid and investment. Clemens et al. (2012) report a one percentage-point increase in Aid/GDP is typically followed several years later by a $0.3-0.5$ percentage points increase in the average investment share of GDP. Temple and Van de Sijpe (2015) find a positive association between aid and 
investment in some models but it is not robust to alternative estimation methods and the exclusion of outliers.

Consumption smoothing creates problems for empirical aid research, even without the extreme assumption that recipients are unable to borrow externally. If aid recipients are able to borrow in international markets to smooth away transitory variation in aid, then there would be little reason to expect any systematic relationship between the short-run patterns of aid receipts and aid-funded expenditure and standard econometric methods based on time-series variation would be inappropriate. A more realistic model might have recipients able to save more easily than they can borrow, so that investment may be cut to smooth consumption if reserves are exhausted and borrowing constraints bind after experiencing a large negative aid shock, but otherwise investment need not react to the short-run timing of aid receipts. A model along these lines might predict the relationship between aid and growth found by Galiani et al. (2014).

If aid recipients can smooth away transitory aid variation by accumulating reserves or borrowing from international capital markets, they would not need to use investment as an instrument of consumption smoothing and this paper's strong short-run connection between aid and investment would be broken. But the empirical challenge of distinguishing between transitory and permanent components of aid would remain. On the basis that policymakers are interested in the economic response to a lasting change in aid, empirical estimates should be based on identifying such changes.

In the data generating process studied here, aid shocks are entirely transitory and have no permanent component, although we may say that each aid recipient received a permanent aid shock at time $t=0$, when its expected level of aid was revealed. In this setting, cross-country variation comparing similar economies that receive different levels of expected aid can potentially identify the effect of varying the level of expected aid. However, if we are interested in modeling the effect of permanent aid shocks, then strictly speaking such shocks should be incorporated into the data generating process in the sense that agents should be aware of the possibility. In an empirical context, Fisher and Seater (1993) observe that "the consequences of an event cannot be inferred if the event has not occurred" which here means that unless the aid process is non-stationary, we cannot infer the impact 
of a permanent change in aid. ${ }^{25}$ In practice, because aid recipients have been denied access to credit markets in which they may borrow (or lend) in anticipation of a positive (or negative) permanent shock, this omission is likely to be quantitatively unimportant in the current setting. However, in future work it would be interesting to incorporate low frequency aid regime switching into the data generating process, to introduce variation in the level of aid expected over some reasonably lengthy (expected) period of time, and consider how empirical researchers could identify the response to and aid regime switch.

\section{Conclusion}

This paper has presented a theoretical case study which that suggest empirical researchers must distinguish between transitory and permanent components of foreign aid, if they wish to identify its long-run effects. To the extent that aid recipients allow investment to fluctuate so that they can smooth consumption in the face of volatile aid flows, conventional empirical methods will pick up the short-run response to transitory aid variation and wrongly extrapolate that into estimates of a long-run response. In particular, standard methods overstate the long-run effect on investment and understate the long-run effect on consumption. Output growth regressions may also suffer from similar problems.

In addition, conventional aid-and-growth regressions may be misspecified because they do not allow for aid to affect convergence but rather position aid as a determinant of steady-state. This paper has also provided an example in which the flexibility of the Local Projections method outperforms more conventional methods, when computing impulse response functions.

The arguments presented suggest that empirical aid research would benefit from more careful theoretical articulation. The analysis also suggests that attempts to identify longlasting aid shocks in the data may prove fruitful, and that empirical models should allow for aid to affect the pace of convergence.

${ }^{25}$ If the aid process is stationary, any shock to aid will be transitory by definition. 


\section{References}

Aguiar, M. and G. Gopinath (2007). Emerging market business cycles: The cycle is the trend. Journal of Political Economy 115(1), pp. 69-102.

Arellano, C., A. Buli $£_{j}$, T. Lane, and L. Lipschitz (2009). The dynamic implications of foreign aid and its variability. Journal of Development Economics 88(1), 87 - 102.

Arellano, M. and S. Bond (1991). Some tests of specification for panel data: Monte carlo evidence and an application to employment equations. The Review of Economic Studies 58(2), 277-297.

Arndt, C., S. Jones, and F. Tarp (2010). Aid, growth, and development: Have we come full circle? Journal of Globalization and Development. 1(2).

Arndt, C., S. Jones, and F. Tarp (2013). Assessing foreign aid's long-run contribution to growth in development. Working Papers WP/2013/072, UNU-WIDER.

Barro, R. J. and X. Sala-i Martin (1992). Convergence. Journal of Political Economy 100(2), pp. 223-251.

Binder, M. and M. Pesaran (1999). Stochastic growth models and their econometric implications. Journal of Economic Growth 4(2), 139-183.

Blundell, R. and S. Bond (1998). Initial conditions and moment restrictions in dynamic panel data models. Journal of Econometrics 87(1), 115-143.

Brock, W. and L. Mirman (1972). Optimal economic growth and uncertainty: The discounted case. Journal of Economic Theory 4(3), 479-513.

Brueckner, M. (2013). On the simultaneity problem in the aid and growth debate. Journal of Applied Econometrics 28(1), 126-150.

Brueckner, M. and M. Gradstein (2013). Effects of transitory shocks to aggregate output on consumption in poor countries. Journal of International Economics 91(2), 343-357.

Bruno, G. S. (2005). Approximating the bias of the LSDV estimator for dynamic unbalanced panel data models. Economics Letters 87(3), 361-366. 
Buffie, E. F., S. A. O'Connell, and C. Adam (2010). Fiscal inertia, donor credibility, and the monetary management of aid surges. Journal of Development Economics 93(2), 287 - 298.

Bulír, A. and A. J. Hamann (2008). Volatility of development aid: From the frying pan into the fire? World Development 36(10), 2048-2066.

Burnside, C. and D. Dollar (2000). Aid, policies, and growth. American Economic Review 90(4), 847-868.

Carroll, C. D. (2001). Death to the log-linearized consumption Euler equation! (and very poor health to the second-order approximation). The B.E. Journal of Macroeconomics 1(1), $1-38$.

Chari, V. V., P. J. Kehoe, and E. McGrattan (1997). The poverty of nations: a quantitative investigation.

Chenery, H. B. and A. M. Strout (1966). Foreign assistance and economic development. The American Economic Review 56(4), pp. 679-733.

Clemens, M. A., S. Radelet, R. R. Bhavnani, and S. Bazzi (2012). Counting chickens when they hatch: Timing and the effects of aid on growth. Economic Journal 122, 590-617.

Deaton, A. (1997). The Analysis of Household Surveys. Baltimore: Johns Hopkins University Press.

DeJong, D. N. and C. Dave (2011). Structural macroeconometrics. Princeton University Press.

Dreher, A., S. Lohmann, et al. (2015). Aid and growth at the regional level. Technical report, CEPR Discussion Papers.

Easterly, W. (2003). Can foreign aid buy growth? The Journal of Economic Perspectives 17(3), pp. 23-48.

Fisher, M. E. and J. J. Seater (1993). Long-run neutrality and superneutrality in an arima framework. The American Economic Review 83(3), pp. 402-415.

Galiani, S., S. Knack, L. C. Xu, and B. Zou (2014). The effect of aid on growth: Evidence from a quasi-experiment. Mimeo. 
Ghosh, A. R. and J. D. Ostry (1995). The current account in developing countries: A perspective from the consumption-smoothing approach. The World Bank Economic Review 9(2), 305-333.

Hauk, WilliamR., J. and R. Wacziarg (2009). A Monte Carlo study of growth regressions. Journal of Economic Growth 14(2), 103-147.

Hsieh, C.-T. and P. J. Klenow (2007). Relative prices and relative prosperity. American Economic Review 97(3), 562-585.

Jappelli, T. and L. Pistaferri (2010). The consumption response to income changes. Annual Review of Economics 2(1), 479-506.

Jarotschkin, A. and A. Kraay (2013). Aid, disbursement delays, and the real exchange rate. Policy Research Working Paper WPS6501, World Bank.

Jones, C. I. (1995). Time series tests of endogenous growth models. The Quarterly Journal of Economics 110(2), pp. 495-525.

Jorda, O. (2005). Estimation and inference of impulse responses by local projections. American Economic Review 95(1), 161-182.

Juselius, K., N. F. Mï $£_{j} l$ ler, and F. Tarp (2014). The long-run impact of foreign aid in 36 African countries: Insights from multivariate time series analysis. Oxford Bulletin of Economics and Statistics 76(2), 153-184.

Kiviet, J. F. (1995). On bias, inconsistency, and efficiency of various estimators in dynamic panel data models. Journal of Econometrics 68(1), 53-78.

Lee, K., M. H. Pesaran, and R. Smith (1997). Growth and convergence in multi-country empirical stochastic Solow model. Journal of Applied Econometrics 12(4), 357-92.

Mankiw, G., D. Romer, and D. N. Weil (1992). A contribution to the empirics of economic growth. The Quarterly Journal of Economics 107.

Mekasha, T. J. and F. Tarp (2013). Aid and growth: What meta-analysis reveals. Journal of Development Studies 49(4). 
Mendoza, E. G. and P. M. Oviedo (2006). Fiscal policy and macroeconomic uncertainty in developing countries: The tale of the tormented insurers. Working Paper 12586, National Bureau of Economic Research.

Nickell, S. J. (1981). Biases in dynamic models with fixed effects. Econometrica 49(6), 141726.

Obstfeld, M. (1999). Foreign resource inflows, saving, and growth. In K. Schmidt-Hebbel and L. Serven (Eds.), The Economics of Saving and Growth. Cambridge: Cambridge University Press.

Obstfeld, M. and K. Rogoff (1995). The intertemporal approach to the current account. Volume 3 of Handbook of International Economics, pp. 1731 - 1799. Elsevier, Amsterdam.

Rajan, R. G. and A. Subramanian (2008). Aid and growth: What does the cross-country evidence really show? The Review of Economics and Statistics 90(4), 643-665.

Roodman, D. (2009). How to do xtabond2: An introduction to difference and system GMM in Stata. Stata Journal 9(1), 86-136.

Stachurski, J. (2002). Stochastic optimal growth with unbounded shock. Journal of Economic Theory 106(1), 40-65.

Stigler, G. (1977). The conference handbook. The Journal of Political Economy 85, 441-443.

Temple, J. (2010). Aid and condtionality. In M. Rosenzweig and D. Rodrik (Eds.), Handbook of Development Economics 5, pp. 4415-4523. Elsivier, North Holland.

Temple, J. R. W. and N. Van de Sijpe (2015). Foreign Aid and Domestic Absorption. Discussion Paper 15/658], University of Bristol.

Townsend, R. M. (1995). Consumption insurance: An evaluation of risk-bearing systems in low-income economies. The Journal of Economic Perspectives 9(3), pp. 83-102.

Werker, E., F. Z. Ahmed, and C. Cohen (2009). How is foreign aid spent? evidence from a natural experiment. American Economic Journal: Macroeconomics 1(2), 225-44. 